\title{
La lengua ante una nueva realidad social de la mujer: construcción del género en portavoza y árbitra
}

\author{
Paula Albitre Lamata
}

Albitre Lamata, P. (2021). La lengua ante una nueva realidad social de la mujer: construcción del género en portavoza y árbitra. Revista de Filología y Lingüística de la Universidad de Costa Rica, 47(2), e46767. doi: https://doi.org/10.15517/rfl.v47i2.46767

\section{(c) $\mathbb{P Q \Theta O}$}

Doi: https://doi.org/10.15517/rfl.v47i2.46767

URL: https://revistas.ucr.ac.cr/index.php/filyling/index 
Revista de Filología y Lingüística de la Universidad de Costa Rica

ISSN: 0377-628X

ISSN: 2215-2628

filyling@gmail.com

Universidad de Costa Rica

Costa Rica

\title{
La lengua ante una nueva realidad social de la mujer: construcción del género en portavoza y árbitra *
}

\author{
Albitre Lamata, Paula \\ La lengua ante una nueva realidad social de la mujer: construcción del género en portavoza y árbitra * \\ Revista de Filología y Lingüística de la Universidad de Costa Rica, vol. 47, núm. 2, e46767, 2021 \\ Universidad de Costa Rica, Costa Rica \\ Disponible en: https://www.redalyc.org/articulo.oa?id=33266553016 \\ DOI: https://doi.org/10.15517/rfl.v47i2.46767
}

\section{(c) $(1) \Theta(\Theta$}

Esta obra está bajo una Licencia Creative Commons Atribución-NoComercial-SinDerivar 3.0 Internacional. 


\section{La lengua ante una nueva realidad social de la mujer: construcción del género en portavoza y árbitra*}

\section{The Language in the Face of a New Social Reality of Women: Construction of Gender in Portavoza and Arbitra}

Paula Albitre Lamata*

Universidad Complutense de Madrid, Instituto

Universitario Menéndez Pidal, Madrid, España

palbitre@ucm.es

(iD https://orcid.org/0000-0001-5917-2999
DOI: https://doi.org/10.15517/rfl.v47i2.46767

Redalyc: https://www.redalyc.org/articulo.oa? $\mathrm{id}=33266553016$

Recepción: 18 Septiembre 2020

Aprobación: 15 Octubre 2020

\section{Resumen:}

En el presente trabajo se analizan las relaciones entre lengua, sociedad e ideología. Para ello, se ha estudiado la evolución de dos femeninos de profesiones (portavoza y árbitra) en tres corpus del español (CORDE, CREA y CORPES XXI) y en las distintas ediciones de los diccionarios de la Academia. Los resultados reflejan que los cambios sociohistóricos que afectaron a las mujeres a lo largo del siglo XX condicionan la marcación del género femenino, ya sea a través de la concordancia o de la forma flexionada. Desde una perspectiva lexicológica, se reflexiona sobre los supuestos epistemológicos del sexismo lingǘstico que subyacen en la lengua española y, más en concreto, en la categoría de género.

PALABRAS ClAVE: variación lingüística, género gramatical, sexismo lingüístico, lexicología, lingüística de corpus.

\section{Abstract:}

This essay analyses the relationships between language, society, and ideology. To this end, the evolution of two female professions (portavoza and árbitra) has been studied in three corpora of Spanish (CORDE, CREA, and CORPES XXI) and in the different editions of the dictionaries of the Academy. The results reflect that socio-historical changes that affected women throughout the twentieth-century condition the marking of the female gender, either through concordance or flexed form. From a lexicological perspective, this essay reflects on the epistemological assumptions of linguistic sexism that underlie the Spanish language and, more specifically, the category of gender.

KEYWORDS: linguistic variation, grammatical gender, linguistic sexism, lexicology, corpus linguistics.

El lenguaje no solo crea y piensa por los hablantes, sino que guía a la vez sus emociones y dirige su personalidad psíquica (Klemperer, La lengua del Tercer Reich, 2001, p. 31).

\section{LA LENGUA COMO CONSTRUCTO SOCIAL: ESPEJO DE LA REALIDAD}

Uno de los medios de manipulación ideológica más empleados por los grupos dominantes es el discurso, pues sirve no solo para mostrar ideas, sino también para implantar una ideología. Así, el control se puede ejercer a través del discurso. El sexismo, como sistema de dominación, también recurre al poder discursivo para imponer su ideología. La concepción del mundo del grupo que tiene el control se basa en las reglas que

* El estudio forma parte de la investigación realizada en el marco del proyecto de investigación titulado "Variación pragmática en la expresión de la cortesía en español" financiado por UCM-Grupo Santander (REF PR87/19-2254), así como del I+D+ i titulado "Los procesos de la gestión de la imagen y la (des)cortesía: perspectivas históricas, lingüísticas y discursivas" (PID2019-107668GB-I00), dirigidos por las doctoras Iglesias Recuero e Hidalgo Downing. 
sirven para entender la realidad según sus propios intereses, crear las actitudes que a ellos les convienen y juzgar los comportamientos según se ajusten a los fines que pretenden conseguir.

Tal como recoge Buxó Rey (1988, p. 72), "la desigualdad y la dominación necesitan preservarse manteniendo las asimetrías en el acceso y en el uso de la lengua, el ritual, la religión y los mitos que validan y regulan la producción y reproducción sociales". El sistema se orienta a favorecer y mantener el poder y estatus socioeconómico del hombre, en definitiva, asienta la dominación masculina.

Un buen indicio del poder discursivo son las definiciones de 'masculino' y 'femenino' en los diccionarios, productos lingüístico-culturales que no solo fijan la lengua, sino también la ideología. Hasta la 22. ${ }^{a}$ edición del $\operatorname{DLE}^{1}$ (es decir, la anterior a la actual), 'femenino' se definió como 'débil, endeble' ${ }^{2}$, mientras que 'masculino' como 'varonil, enérgico, valiente'. Dos definiciones que situaban a cada sexo en polos opuestos, desde la debilidad de 'femenino' hasta la firmeza de 'masculino' (RAE, 2001). En definitiva, una estrategia para devaluar a las mujeres dentro del patriarcado ${ }^{3}$. Evidentemente, esas acepciones aparecían en el diccionario no porque la Academia quisiese imponerlas y difundirlas en la sociedad, sino porque ya existían.

En la edición actual del diccionario estas acepciones han sido suprimidas, pero su uso en la lengua, desgraciadamente, se mantiene. Esta atribución a cada sexo de distintas características, perjudicando siempre a la mujer, aparece con bastante frecuencia en expresiones de nuestra lengua: perro/perra, zorro/zorra, gallo/gallina, afeminado/caballeroso, niña/machote; la cobardía se asocia con términos como 'mujercitas' o 'mamitas' y se agrava el desprecio al dirigirse a un hombre homosexual con términos femeninos como 'mariquita', 'reinona' o 'maricona'. Esta extensa lista de expresiones 'populares' despectivas nos revela que la balanza del discurso está 'trucada', no es paritaria, sino que es maniquea y sexista. Es indudable que este tipo de metáforas discursivas reposan sobre una moral antropocéntrica de dominio; sin embargo, hasta qué punto el uso de determinados términos, como portavoz o árbitro, fuera de la construcción metafórica del lenguaje, reflejan la discriminación de la mujer en el lenguaje.

El discurso de las élites de poder ha sido, y es aún hoy, expropiable, la sociedad avanza y con ella su pensamiento. Los pilares de la ideología sexista que infravaloran a la mujer llevan tambaleándose siglos, pero es ahora cuando están próximos a caer. Cuando el grupo dominante y su ideología se desplomen, su discurso podrá resignificarse para construir nuevos modelos paritarios. El primer paso para conseguir la derrota del sexismo lingüístico ${ }^{4}$ es admitir que entre los mecanismos de control del patriarcado se encuentra el discurso. Como expone Islas Azaïs (2005, p. 21), "el lenguaje contribuye a mantener invisibles algunas de las relaciones de dominación y marginación que tienen lugar bajo la superficie, aparentemente neutral, del orden establecido, de lo que se considera convencionalmente correcto o normal".

La polémica suscitada por términos como portavoza o árbitra radica en el uso del género gramatical. Por tanto, para comprender por qué la sociedad prefiere una forma u otra, deberemos realizar una aproximación gramatical a la categoría del género en nuestra lengua. Al hablar de género, los filólogos y lingüistas hacemos referencia a la acepción no 8 del DLE, estrictamente gramatical: "Categoría gramatical inherente en sustantivos y pronombres, codificada a través de la concordancia en otras clases de palabras y que en pronombres y sustantivos animados puede expresar sexo". Más moderno y reciente es el significado que equipara género y sexo ${ }^{5}$ en la acepción $\mathrm{n}^{\circ}$ 3: "Grupo al que pertenecen los seres humanos de cada sexo, entendido este desde un punto de vista sociocultural en lugar de exclusivamente biológico”. En este trabajo, al mencionar 'género' se hará referencia a la acepción gramatical.

El español es una lengua que tiene dos géneros: masculino y femenino; por tanto, tiene una concordancia binaria. Otras lenguas, como el inglés, no presentan género(s) y, aunque parezca contradictorio, el mundo anglosajón ha aportado una mayor sensibilidad hacia estas cuestiones ${ }^{6}$. Volviendo a nuestra lengua, el género masculino es, por defecto, el no marcado, el que incluye; el género femenino, el marcado, el que excluye. Esta concordancia binaria está presente en la conciencia lingüística de los hablantes de español. Las palabras, en función de cómo manifiestan el género, se pueden clasificar en tres bloques: 
a) Flexión: términos que tienen distintas terminaciones para el masculino y el femenino: el abogado/la abogada; el jefe/la jefa; el profesor/la profesora; el secretario/la secretaria; el árbitro/la árbitra.

b) Concordancia: términos que presentan una única forma y manifiestan su género, exclusivamente, a través de la concordancia: el cantante/la cantante; el modelo/la modelo; el intérprete/la intérprete; el portavoz/la portavoz.

c) Nombres epicenos: tienen un único género y, por consiguiente, una única concordancia. Pueden referirse indistintamente a individuos de uno u otro sexo: una persona, una víctima, un bebé, un personaje.

Es evidente que todos los socios del Atlético de Madrid, ya sean mujeres u hombres, saben que pueden disfrutar de los descuentos para el 'Día del Socio' que organiza el club cada año; pero, por qué es así y no al revés, por qué no incluye el femenino. Para poder responder a esta pregunta, debemos remontarnos hasta el indoeuropeo. Y sí, es posible, como señala Álvarez de Miranda (2018, p. 20), que "la condición de género no marcado que tiene el masculino sea trasunto de la prevalencia ancestral de patrones androcéntricos y patriarcales". Ya en 1995, Lakoff (1995, p. 91) asociaba este dominio lingüístico de lo masculino sobre lo femenino con el hecho de que los hombres han sido los escritores y los agentes de la lengua.

Frente a esta hipotética base discriminatoria, Álvarez de Miranda (2018, p. 21) acepta que en una sociedad "es más difícil rechazar el binarismo sexual que el binarismo gramatical”. Los cambios gramaticales y lingüísticos se tienden a producir de abajo hacia arriba y tras un refrendo mayoritario de los hablantes, no ocurren por decreto de arriba hacia abajo. De igual forma que un hablante no puede crear un nuevo tiempo verbal, no se puede crear una nueva categoría de género.

Aunque no son comparables, por el marcado componente social que envuelve la semántica y referencialidad del género, es cierto que esta categoría presenta unas características compartidas por otros elementos del sistema gramatical. Al igual que hay dos géneros, en español también hay dos números (el singular sería el no marcado frente al plural) y tres tiempos verbales (el presente constituiría el no marcado frente al pasado y futuro). Uno de los problemas en torno al género se basa en asociar, erróneamente, género gramatical y sexo biológico en los sustantivos con referencia animada [+humana]. No es sistemático que el género masculino remita al sexo masculino y el género femenino al sexo femenino. Es cierto que hay epicenos femeninos que representan tanto al sexo masculino como al femenino: persona, eminencia, figura, víctima..., sin embargo, la polémica viene suscitada en los casos de desdoblamiento por marca de flexión (niño/niña. alumnos/alumnas, ministros/ministras...) o por artículo (el/la modelo. el/la artista. el /la cantante).

Ante estos últimos ejemplos, hay sectores de mujeres que se sienten excluidas, discriminadas e invisibilizadas por el uso genérico del masculino. Gramaticalmente, la respuesta es sencilla: el masculino es el género no marcado del español, por consiguiente, es inclusivo del género femenino y, así, de las mujeres. Esta característica, tan fosilizada en los hablantes, parece a priori inamovible. Los cambios en las lenguas son realmente complicados, modificar las reglas gramaticales no depende de un hablante individual, tampoco de grupos, ni siquiera de las instituciones que 'regulan' la norma lingüística, como la RAE y la ASALE. Sin embargo, un elemento de la lengua puede ir cayendo en desuso, lo que abriría la puerta al cambio. De igual forma que actualmente el futuro simple ('esta tarde iréal cine') presenta una frecuencia de uso mínima en el español peninsular, en favor de la perífrasis incoativa 'ir a + infinitivo' ('esta tarde voy a ir al cine'); el género podría, con el paso del tiempo, mudar de características para ceder el masculino su condición de no marcado al femenino.

Aunque en un futuro el género femenino fuese el no marcado, el inclusivo, no todo sería tan sencillo. Llevamos años escuchando las propuestas del lenguaje inclusivo que defiende, precisamente, esta condición genérica del género femenino. Uno de los errores más frecuentes en el uso del lenguaje inclusivo es la concordancia. No solo los sustantivos tienen género, también lo tienen los adjetivos, los pronombres, los artículos y los participios; de modo que, si se altera el género de un nombre, el resto de palabras con las que concuerda también deberán hacerlo. La consecuencia de un mal uso de la concordancia de género suele 
desembocar en el incremento del rechazo hacia el lenguaje inclusivo por parte de sus detractores. Las críticas a la diputada española M. Beitialarrangoitia por no establecer la concordancia correspondiente entre el sujeto (femenino) y el predicativo (masculino) fueron muy sonadas, allá por 2016: "Nosotras, que aspiramos a representar a todas las personas que, votándonos o no, han hecho mayoritaria esa apuesta por la ruptura, venimos dispuestos a hacer oír el clamor" (Real Academia de Extremadura, s. f., párr. 6, el subrayado es nuestro).

Su intervención en el Congreso de los Diputados de España, en un intento de uso del lenguaje inclusivo, terminó por mostrar uno de los problemas de este nuevo discurso: su falta de sistematización e interiorización en los hablantes. Aún en la actualidad, la concordancia en la sintaxis es un escollo para la difusión del lenguaje inclusivo, escollo que se acentúa en los casos de duplicación ligada al sexo (los/las alumnos/alumnas españoles) españolas tienen notas más bajas que los/las franceses/francesas). Este fenómeno, que busca otorgar mayor visibilidad a las mujeres, choca con una barrera de nuestra lengua: la economía lingüística ${ }^{7}$. Esta tendencia al desdoblamiento innecesario, cuando se pretende hacer referencia a un grupo mixto único, es antieconómica. No solo produce incorrecciones, anacolutos y discordancias (que revelan precisamente la artificialidad de este tipo de usos), sino que añade dificultades innecesarias a la comprensión y hace innecesariamente más laboriosa la recuperación del mensaje que se quiere transmitir (Escandell-Vidal, 2020, p. 239). Aunque es una opción totalmente respetable, es de esperar que en un futuro no triunfe, ya que numerosos estudios (Gutiérrez Ordóñez, 1989; Prieto, 1967; Moreno Cabrera, 2002 o Escandell-Vidal, 2020) han constatado que los hablantes optan por simplificar su mensaje, buscar la comodidad y minimizar su esfuerzo a la hora de comunicarse, principios totalmente opuestos a la duplicación.

La realidad nos muestra la complejidad de este debate lingüístico. El primer paso está dado: ser conscientes de que una sociedad también se construye lingüísticamente y que el propio sistema lingüístico puede contribuir a una situación de desigualdad discriminatoria hacia la mujer, especialmente en determinados sectores léxicos, como el referido a los atributos físicos de las mujeres y a las relaciones sexuales.

La importancia de estudiar la existencia del sexismo lingüístico en español es incuestionable en nuestros días. Así lo avalan numerosos autores (García Meseguer, 1977, 1994; Suardiaz, 2002; Calvo, 2017; Álvarez de Miranda, 2018; Gutiérrez Ordoñez, 2018; Grandes, 2018; Grijelmo, 2019; Sarlo y Kalinowski, 2019; Corroto, 2020; entre otros) que parten de la interrelación entre lengua, moral y realidad. Por tanto, es esperable que la sociedad y su ideología, independientemente de si es o no androcentrista, se vean reflejadas en el uso de su lengua en general y en la categoría de género en particular. Frente a esta hipótesis, encontramos otra línea de opinión que defiende que la lengua no es inherentemente sexista, por lo que no invisibiliza a la mujer (Calero, 1999; Lledó, 2009; Bengoechea, 2015; Guerrero, 2017, 2019; Mendívil, en prensa; entre otros). Precisamente este contraste de visiones es lo que mantiene vivo este debate científico.

El acceso de la mujer a actividades y empleos en los que su presencia, hasta hace no muchos años, era simbólica o inexistente, ha dinamizado la formación de femeninos específicos para determinadas profesiones o cargos. En este trabajo se abordará, desde una perspectiva lexicográfica, la historia de los términos portavoza y árbitra, en relación con otros términos que también presentan rasgos similares (alcaldesa o diputada). El objetivo es constatar cómo influye el contexto sociopolítico y la condición de la mujer en el uso de la lengua. Para ello se analizarán las muestras de estos términos en tres corpus del español (CORDE, CREA y CORPES XXI) y se estudiarán sus definiciones en las distintas ediciones de los diccionarios de la Academia.

\subsection{El cambio lingüístico}

Portavoza, alcaldesa, diputada y árbitra han experimentado cambios lingüísticos como tantas otras palabras y elementos de nuestra lengua. La noción de cambio suele implicar, como señala Lüdtke (1998a, p. 6), que un cierto objeto exista continuamente en un espacio de tiempo $t i \rightarrow t j$ y que las cualidades que posee en los 
momentos $t i \rightarrow t j$ sean diferentes. Es un hecho consabido que las lenguas cambian con el paso del tiempo y con ellas cambia la realidad cognitiva de sus hablantes. Pero, ¿por qué existen los cambios lingüísticos? La respuesta la encontramos en los mismos hablantes. El lenguaje existe por y para la comunicación. Quien habla intenta influir en sus interlocutores usando un discurso determinado. Como las situaciones comunicativas varían con los años, también lo hacen las estrategias verbales de los hablantes. El cambio lingüístico no es más que el resultado de que una lengua sigue viva.

"El cambio lingüístico es un fenómeno lento pero ineluctable" (Lüdtke, 1998a, p. 29). Entre un padre y su hijo no apreciaremos diferencias; sin embargo, desde una perspectiva cronológica, que abarque varias generaciones, se comprueba que la lengua efectivamente ha cambiado. Lüdtke (1998b) establece tres fases en el cambio lingüístico, en donde unifica el cambio semántico con el léxico y el sintáctico:

\section{INNOVACIÓN $\rightarrow$ DIFUSIÓN $\rightarrow$ RESULTADO}

Como hablantes de una lengua vamos de lo concreto a lo abstracto, de lo objetivo a lo subjetivo, de modo unidireccional. Precisamente, esta unidireccionalidad del cambio lingüístico es la base de la Teoría de Lakoff y Johnson (1980). Estos teóricos destacaron el papel trascendental del ser humano en la concepción del significado: "nuestra mente está encarnada en un cuerpo con el que nos podemos relacionar con el entorno a través de los distintos sentidos, la manipulación de objetos y la percepción del espacio y el movimiento" (Lakoff y Johnson, 1980, p. 50).

Las proyecciones en la lengua no son arbitrarias, sino que están basadas en nuestras experiencias personales cotidianas y dependen del contexto ('context model', Lakoff y Johnson, 1980). Las palabras no solo poseen el significado que les otorga el diccionario, sino que también poseen el otorgado por los miembros de una sociedad, por sus hablantes. Las palabras son unidades vivas que, asimismo, varían en función de los cambios sociales y las nuevas realidades. En un cambio lingüístico no solo actúa la norma de la lengua sino también su uso, pero siempre de forma unidireccional, desde lo concreto a lo abstracto.

Es obvio que primero se inventó el internet (o la internet para otros) y luego la palabra 'internet'. Con los términos que centran este estudio ocurre lo mismo, primero se produjo un cambio social y luego un cambio lingüístico (morfológico, en el caso de portavoza, diputada y árbitra; semántico, en el de alcaldesa). Los límites a una lengua no los pone el diccionario, ni siquiera la Academia, sino sus hablantes. Como expone Pons (2018, párr. 1), "a su manera, las palabras también son empujadas por la vida, obligadas a adaptarse a las realidades y necesidades de un tiempo y un lugar”.

\section{Portavoza: el problema de los sustantivos comunes en CuAnto al género}

En febrero de 2018, Irene Montero (en ese momento portavoz en el congreso de España del partido Unidos Podemos $^{8}$ ) acuñó por primera vez el término portavoza con el fin de "dar mayor "visibilidad" a las mujeres en su lucha por la igualdad de derechos con los hombres" (Marcos, 2018, párr. 1): "Mañana, hay en el círculo de Bellas Artes, en la sala María Zambrano, a las siete de la tarde, un acto con diferentes portavoces y portavozas del grupo parlamentario confederal”. -Irene Montero (El imparcial, 2018, 0:00-0:10). Esta intervención generó numerosas críticas, pues una gran parte del público lo entendió como una 'provocación gratuita' ${ }^{9}$; pero también dio paso a una reflexión lingüística sobre cómo actúan las palabras.

En este trabajo se intentará, desde una perspectiva diacrónica y lingüística, analizar la conformación de portavoza. El estudio del término portavoz ${ }^{10}$, en los corpus CORDE, CREA y CORPES XXI, revela un vacío de aparición en documentos escritos de siete siglos. La primera aparición documentada de portavoz ${ }^{11}$ data de 1356, en la obra Fuero viejo de Castilla. Para encontrar la siguiente muestra se debe esperar hasta comienzos del siglo XX, en concreto hasta 1900, en la obra Evolución política del pueblo mexicano de Justo Sierra.

Aún más tardía será la aparición de portavoz junto al artículo femenino como marca de género (la portavoz), fechada el 2 de marzo de 1980, en un artículo de política en el periódico El País (España) ${ }^{12}$. Las muestras 
de la portavoz aparecen mayoritariamente en España (80.29\%), relacionadas con la temática política (64.85 $\%)$, seguidas del ocio y la vida cotidiana $(9 \%)^{13}$. Es congruente que la política constituya uno de los pilares en la evolución del término portavoz.

Retomemos el quid de la cuestión: ¿por qué surge portavoza? Irene Montero aplica un criterio formal, 'flexionando' el término portavoz, con el fin de marcar el género femenino. Como se ha mencionado en el primer apartado, el morfema flexivo no es el único mecanismo para indicar el género en nuestra lengua. De hecho, el término portavoz distingue el género a través de la concordancia y no del morfema: el portavoz/ la portavoz. Portavoz no "flexiona" pero sí tiene dos géneros, por lo que remite de igual forma a mujeres y a hombres.

Es posible que Montero, como señala Álvarez de Miranda (2018, p. 41), "siguiese la lógica gramatical ensayando la flexión de otros sustantivos agudos terminados en -z", como juez/jueza o aprendiz/aprendiza. Estos términos, cuando fueron catalogados de 'comunes en cuanto al género', dejaron de ser exclusivamente masculinos y comenzaron a 'flexionar'. Obviamente, la historia del término jueza discurre de forma paralela a la incursión de la mujer en la administración de justicia. En 1970, jueza seguía manteniendo (todavía) la acepción de 'esposa del juez'.

Sin embargo, si profundizamos más en la etimología del término portavoz, constatamos que su raíz es, en sí misma, femenina. Portavoz es un nombre compuesto a partir de la unión del verbo portar y del sustantivo femenino voz: 'el que porta la voz'. Además, desde el punto de vista morfológico, su conformación es sencilla de vislumbrar para los hablantes: todos somos capaces de reconocer la presencia del sustantivo voz, invariable y, por ende, 'inflexionable'. Morfológicamente, portavoz hace referencia tanto a hombres como a mujeres, por lo que el desdoblamiento resulta innecesario, redundante y superfluo. La morfología constata que no es más femenino portavoza que la portavoz, por mucho que la intención de Montero fuese dar 'mayor visibilidad a las mujeres'.

Parece que el punto de partida de Montero para escoger este 'neologismo', obviando el trasfondo feminista de este debate, fue la asociación del morfema flexivo -a con femenino y -o con masculino; en definitiva, enlazó erróneamente las nociones de género gramatical con sexo biológico. Es cierto que hoy portavoza no está aceptado por la norma ${ }^{14}$ y tampoco presenta una frecuencia de uso elevada entre los hablantes de nuestra lengua. No obstante, contamos en español con ejemplos de términos que, en su origen, eran invariables y actualmente sí marcan el género mediante flexión. Este sería el caso de palabras como testigo o aprendiz. La Tabla 1 muestra la evolución de estos sustantivos, al tiempo que los contrasta con portavoz siguiendo tres parámetros:

1. Invariabilidad

2. Marca de género mediante la concordancia (artículo la)

3. Marca de género mediante el morfema flexivo (o/a)

TABLA 1.

Evolución de tres sustantivos comunes en cuanto al género

\begin{tabular}{|l|l|l|l|l|l|}
\hline El testigo & 1129 (España) & La testigo & 1665 (Argentina) & Testiga & 1984 (Colombia) \\
\hline El aprendiz & 1328 (España) & La aprendiz & 1991 (España) & Aprendiza & 1975 (España) \\
\hline El portavoz & 1356 (España) & La portavoz & 1980 (España) & Portavoza & 2018 (España) \\
\hline
\end{tabular}

La tabla refleja cómo las muestras en las que se diferencia el género femenino, bien por la concordancia o por la flexión, aparecen con posterioridad respecto a la forma invariable. Esto, como se expondrá seguidamente, está estrechamente vinculado con los procesos sociales de la historia y con el papel que la mujer ha desempeñado en ella. 
También se debe estudiar quién introduce, por primera vez ${ }^{15}$, estos términos. En los casos de aprendiza (Francisco Umbral ${ }^{16}$ y Antonio Gala ${ }^{17}$ en 1975) y portavoza (Irene Montero en 2018) han sido acuñados por personas influyentes en la sociedad del momento, catalogados tradicionalmente como líderes lingüisticos. $\mathrm{Si}$ es necesario un acuerdo mayoritario de los hablantes para habilitar procesos de cambios gramaticales y lingüísticos, puede que se facilite su expansión si estos mismos cambios son iniciados por líderes lingüisticos. Sin embargo, nadie puede asegurar que estas "palabras de autor" triunfen y permanezcan en el tiempo.

\subsection{La evolución de portavoz: influjo del contexto sociohistórico}

España, a lo largo de las últimas décadas y gracias al régimen constitucional vigente, ha experimentado un cambio sustancial con la incorporación de la mujer a todos los espacios sociales y de discusión pública, acompañado de la correspondiente adaptación jurídica que avala dicho cambio. Los cauces de la política y, fundamentalmente, de la situación de la mujer han marcado la evolución de portavoz. Como se muestra en la Figura 1 y la Tabla 2, los datos extraídos de los corpus (CORDE, CREA y CORPES XXI) y diccionarios así lo constatan.

\section{Evolución de portavoz}

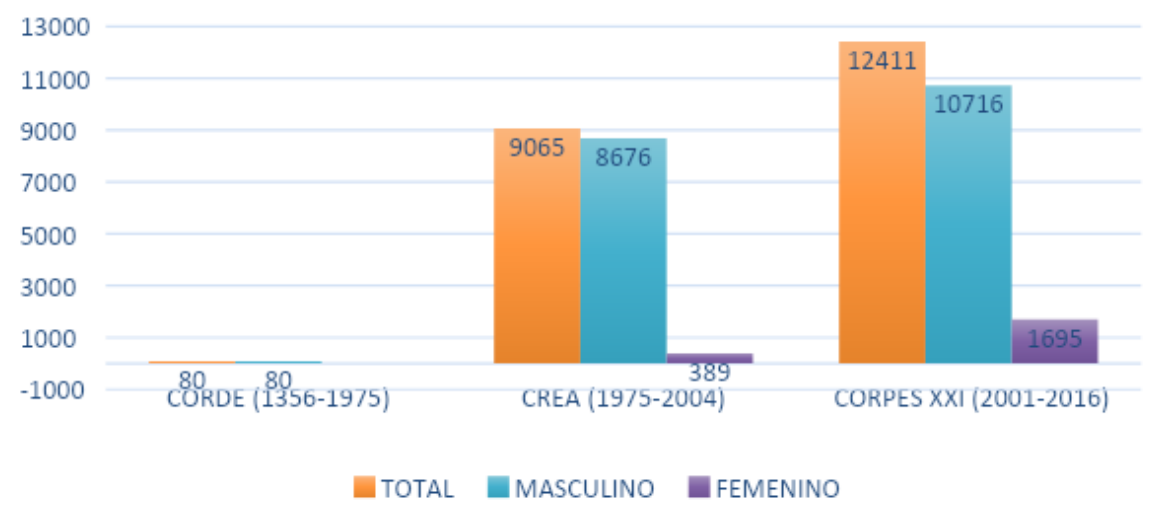

FIGURA 1.

Gráfico generado a partir de los datos del término portavoz en los corpus

TABLA 2.

Desglose de datos extraídos de los corpus sobre el término portavoz

\begin{tabular}{|l|l|l|l|}
\hline & CORDE (1356-1975) & CREA (1975-2004) & CORPES XXI (2001-2016) \\
\hline TOTAL & 80 & 9065 & 12411 \\
\hline El portavoz & $80(100 \%)$ & $8676(95.7 \%)$ & $10716(86.4 \%)$ \\
La portavoz & 0 & $389(4.3 \%)$ & $1695(13.6 \%)$
\end{tabular}

En su origen, portavoz era un epiceno, de género masculino, que hacía referencia 'al que representa o lleva la voz en una escuela, secta u otra colectividad por tener autoridad', acepción recogida en la edición del DRAE de 1925. Hasta 1980, fecha en la que aparece la primera muestra de marcación de género a través de la concordancia, portavoz sigue siendo un epiceno, por lo que se refiere indistintamente a ambos sexos. Si analizamos los datos de la Figura 1 y Tabla 2, observamos cómo las muestras del masculino constituyen casi la totalidad (100 \% CORDE, 95.7 \% CREA) de los ejemplos extraídos hasta 2004. Datos esperables si tenemos 
en cuenta que la portavoz no aparece hasta 1980 y no figura como tal en el DRAE hasta 2001, cuando se reconocen los dos géneros en el término portavoz, que pasa a ser 'común en cuanto al género'.

Igualmente, será en la edición de 2001 cuando se incorpore al diccionario la acepción con connotación política que, en la actualidad, asociamos al término portavoz. Hasta ese momento no había surgido la necesidad de designar, a través de marcas formales de género, a mujeres que ejerciesen el cargo de portavoz, pues no existían. El lenguaje no es más que una evidencia de la discriminación hacia el colectivo femenino en una sociedad que limitaba su presencia a tareas del hogar y cuidado de la familia.

La incursión de la mujer en la política española ocurre a mediados de los años setenta y supone una ruptura con los estereotipos y prejuicios sociales del momento, sustentados en pilares androcéntricos. A pesar de la inmensa labor de las precursoras en el ámbito político, Clara Campoamor, Victoria Kent y Margarita Nelken, diputadas en 1931, las mujeres no tuvieron un papel activo en política hasta la transición democrática.

Durante el franquismo, la emancipación laboral de la mujer constituía una amenaza para la femineidad, la maternidad y la dedicación total al hogar, pilares del prototipo de mujer en la moral nacionalcatólica de la época. Di Febo (2003, p. 29) indica que, a partir de los años cuarenta, "se asiste a una proliferación de manuales de formación de la mujer, editados desde organizaciones falangistas como el Frente de Juventudes y la Sección Femenina”. El fortalecimiento de la ideología patriarcal durante este periodo, según Nicolás y López (1986, p. 370), estuvo condicionado por la concurrencia de varios factores, siendo los más relevantes los medios de comunicación, el sistema educativo y la iglesia. El lugar de la mujer estaba en casa, salvaguardando la estructura familiar, por lo que la política estaba en manos de los hombres, exceptuando el apéndice femenino de la Falange.

La España de los años setenta fue escenario de una serie de cambios que propiciarían una eclosión feminista en la dinámica social y política: expansión económica gracias al fin de la dictadura franquista y a la apertura capitalista, acceso de la mujer al ámbito laboral, la expansión educativa y cultural ${ }^{18}$ y la llegada de textos fundamentales para el movimiento feminista en otros países (como La mistica de la feminidad de Betty Friedan y El segundo sexo de Simone de Beauvoir).

Además, en 1975 se formó en Madrid la Plataforma de Organizaciones de Mujeres, que organizó las Primeras Jornadas por la Liberación de la Mujer, donde se expuso un programa de denuncias y reivindicaciones, entre las que destacan la despenalización del adulterio femenino, la legalización del divorcio y de los anticonceptivos, la equiparación laboral y salarial, etc. Las mujeres, cada vez más conscientes de su identidad y autonomía, comenzaron una lucha para conseguir sus derechos y revertir su constante subrepresentación en la sociedad. Ante el desinterés mostrado por los miembros varones de los partidos hacia la discriminación misógina, surgieron partidos de mujeres organizados de forma independiente:

- Colectivo Feminista de Madrid, organizado por la abogada Cristina Alberdi.

- Partido Feminista de España, creado por Lidia Falcón.

- Movimiento Democrático de la Mujer, creado por militantes del PCE.

- Asociación Democrática de la Mujer, integrada por mujeres militantes del PTE y de la ORT.

Con el desmantelamiento del régimen franquista, en 1977, las mujeres comenzaron a participar en política, lo que explica la escasa frecuencia de muestras relativas al género femenino de portavoz en los corpus del español. La participación y representación de las mujeres en las actividades políticas desde 1977 ha ido en aumento: del 2,4\% de representación femenina en el Senado en las elecciones de junio de 1977 al $40 \%$ estipulado por la Ley de Igualdad en la actualidad.

Este interés en la paridad política está estrechamente vinculado a los datos extraídos de los corpus. Entre 2001 y 2016, los casos de muestras femeninas de portavoz suponen el $13.6 \%$ del total, cifra notablemente superior a la aportada en décadas anteriores: $4.3 \%$ entre 1975 y 2004 y $0 \%$ hasta 1975. 
Más significativo, si cabe, es la consideración de portavoz como forma exclusivamente masculina, aún en la edición del diccionario de 1992. No es sino hasta 2001 cuando el diccionario valida la existencia de dos géneros ( $\mathrm{m}$. y f.) en portavoz.

Siguiendo esta línea evolutiva, era esperable la aparición del desdoblamiento de género: portavoza. Es innegable que la sociedad y el momento influyen en nuestro lenguaje. En España, con respecto a la participación de mujeres en cargos ejecutivos de los principales partidos políticos, se observa una lenta pero progresiva evolución positiva. El desarrollo de nuevos parámetros en una cultura política democrática ha propiciado que cada vez sean más las mujeres que ocupen cargos políticos y que, por ende, sientan la necesidad de encontrar nuevos términos para denominarlos. Este progreso, específicamente en el cargo de portavoz, se constató en la XIII legislatura (21/05/2019 - 02/12/2019), cuando las principales portavocías del Congreso fueron, por primera vez, ocupadas exclusivamente por mujeres ${ }^{19}$. Morfológicamente, el desdoblamiento portavoz/portavoza es baladí; socialmente, es el reflejo de la nueva posición de la mujer.

Llegó el momento en el que las mujeres accedieron al mundo laboral y el lenguaje cambió. En este punto, merecen un comentario los términos 'alcaldesa' y 'diputada'. Los diccionarios seguían la arcaica tradición de presentar las formas femeninas como referencia a la esposa del hombre al que el masculino designa. Como afirma Álvarez de Miranda (2018, p. 43), "esto es algo que por fortuna está hoy periclitado, lo que nos brinda un ejemplo perfecto de cómo la evolución de la sociedad da al traste con determinados usos cuando estos se tornan insostenibles". El desarrollo de la mujer y su toma de conciencia supuso la fecha de caducidad para estos primitivos usos. La búsqueda de la igualdad social entre sexos se comenzó a plasmar en el diccionario.

Hasta la edición del DRAE de 1936, la única acepción que presentaba alcaldesa era la de 'mujer del alcalde'; en ese momento aparece por primera vez, y como segunda acepción, 'mujer que ejerce el cargo de alcalde'. Aunque la primera mujer alcaldesa de la historia de España fuese elegida en 1924, en el municipio alicantino de Quatretondeta, la posibilidad femenina de ejercer este cargo no fue factible hasta los años setenta. Esta baja participación de la mujer en política suele entenderse como el resultado de las diferencias de género en la socialización, derivadas de las políticas de discriminación implantadas durante el régimen franquista. De hecho, la primera mujer al frente de la administración local de una capital de provincia data de 1969, en concreto Bilbao, gobernado por Pilar Careaga entre 1969 y $1975^{20}$. En el caso de alcaldesa, estamos ante un cambio semántico, no morfológico como portavoz, motivado por la nueva situación más paritaria de la mujer, tras su irrupción en el mundo laboral.

En la actualidad, el DLE (RAE, 2014) ha corregido el panorama desafortunado y sexista de ediciones previas, incluyendo en una misma entrada alcalde y alcaldesa y precisando, con la etiqueta 'nombre femenino coloquial', su última acepción (mujer del alcalde):

Alcalde, desa:

1. m. y f. Autoridad municipal que preside un ayuntamiento y que ejecuta los acuerdos de esta corporación, sin perjuicio de sus potestades propias, y es además delegado del Gobierno en el orden administrativo.

2. m. En algunos juegos de naipes, persona que reparte las cartas y no juega.

3. m. Juez ordinario que administraba justicia en un pueblo y presidía al mismo tiempo el concejo.

4. m. p. us. En algunas danzas, principal de ellas o quien las guía y conduce, o gobierna alguna cuadrilla.

5. f. coloq. p. us. Mujer del alcalde.

El caso de diputada es también consecuencia del reclutamiento político femenino. La edición del diccionario de 1927 ya recoge el desdoblamiento de género a través de la flexión: diputado/diputada. Hasta ese momento, el término diputado remitía, indistintamente, a mujeres y hombres. La mujer alcanzó el derecho a ser elegida diputada en 1931, momento en el que se incorporaron a las Cortes las ya mencionadas Campoamor, Nelken y Kent. Paradójicamente, en 1931, el colectivo femenino aún no tenía permitido votar (sufragio pasivo), pero sí podía ser elegido en las Cortes. Meses más tarde, se consiguió el sufragio activo para las mujeres. A pesar de esto, la dictadura franquista relegó a la mujer a un segundo plano, pues la excluyó de la participación política. Tomando las palabras de Franco Rubio (1986, p. 431), "cuanta más responsabilidad y 
poder emanara de un cargo, más se restringía su desempeño a la mujer, mientras que los puestos considerados menos importantes, o con menor capacidad de decisión, como las concejalías, sí solían ponerse en sus manos".

Esta ausencia y exclusión de la mujer en política se ve reflejada en el uso de diputada. Aunque la diputada estuviese aceptado por la norma y figurase en el diccionario desde 1927, todavía encontramos muestras de la diputado en los años setenta, quizás por el valor peyorativo de la forma flexionada:

- Amenazado de muerte por la diputado Margarita Nelken (España, 1970) ${ }^{21}$.

- Uno de ellos, la diputado laborista Maureen Colquhoun, la ha perdido ya (España, 1977) ${ }^{22}$.

El desdoblamiento diputado/diputada sigue una línea evolutiva similar a la de árbitro/árbitra, como se analizará en el siguiente epígrafe, y contraria a la de portavoz.

Diputado y árbitro son sustantivos que 'flexionan' para manifestar su género y, durante años, mantuvieron el término masculino y su concordancia como forma de expresar el género femenino (la diputado/la árbitro). Hasta que no se normalizó la presencia femenina en las $\operatorname{cortes}^{23}$, no se generalizó el uso de la forma flexionada diputada, que hoy empleamos con total naturalidad.

La marca de género está supeditada, de nuevo, a la condición de subordinación y olvido de la mujer. Mientras los detractores de portavoza rechazan y critican su uso por estar fuera de la norma, hay hablantes que no preferían usar diputada ni árbitra, a pesar de ser morfológicamente correctos. Esto refleja, una vez más, que los límites a nuestra lengua no los pone el diccionario, ni la Academia, sino sus hablantes.

\subsection{Lucha de términos: vocera por portavoza}

Una de las recomendaciones críticas a Irene Montero, tras su reivindicación de portavoza, fue su sustitución por vocera, término 'correcto' y 'aceptado' por la norma. El lingüista Bezos, desde la Fundéu, proponía el uso de esta alternativa de la siguiente forma:

[...] vocera, "una palabra perfectamente formada en español que además ya utilizan millones de hablantes". La usan fundamentalmente en Latinoamérica, pero nada impide hacerlo en España. "Si de lo que se trataba era de visibilizar a las mujeres, en lugar de portavoz y portavoza, creando una forma que es de muy poco uso, bien podría haber recurrido a vocero y vocera. Se puede dar visibilidad a las mujeres de muchas formas de muchas maneras. Hay que buscar los recursos y no ir por la vía fácil, sino aplicarlos con tiento y criterio" (Ávila, 2018, párr. 3).

Sin embargo, no siempre es la norma y su (in)corrección lo que rige el uso de nuestra lengua. Si bien es cierto que vocera es normativo, su empleo no es frecuente entre los hablantes. Proponer a la sociedad emplear un término en desuso, olvidado, es, cuando menos, ineficaz.

Portavoz y vocero son sinónimos, ambos hacen referencia a 'persona que habla en nombre de otra, o de un grupo, institución, entidad, etc., llevando su voz y representación’. La historia del español aporta numerosos ejemplos de estas disputas léxicas entre términos en las que, lógicamente, uno acaba imponiéndose y otro es abocado al abandono lingüístico. Las palabras siguen el curso natural de la vida de sus hablantes y, algunas, también desaparecen y mueren.

El origen de vocero es previo al del término portavoz, pues ya en 1127 se constata su primera muestra ${ }^{24}$. No obstante, su frecuencia de uso se redujo de forma significativa al introducirse, posiblemente desde el francés, el término portavoz. Como se muestra en la Figura 2, los datos extraídos de los corpus revelan esta tendencia al alza de portavoz, en detrimento de vocero: 


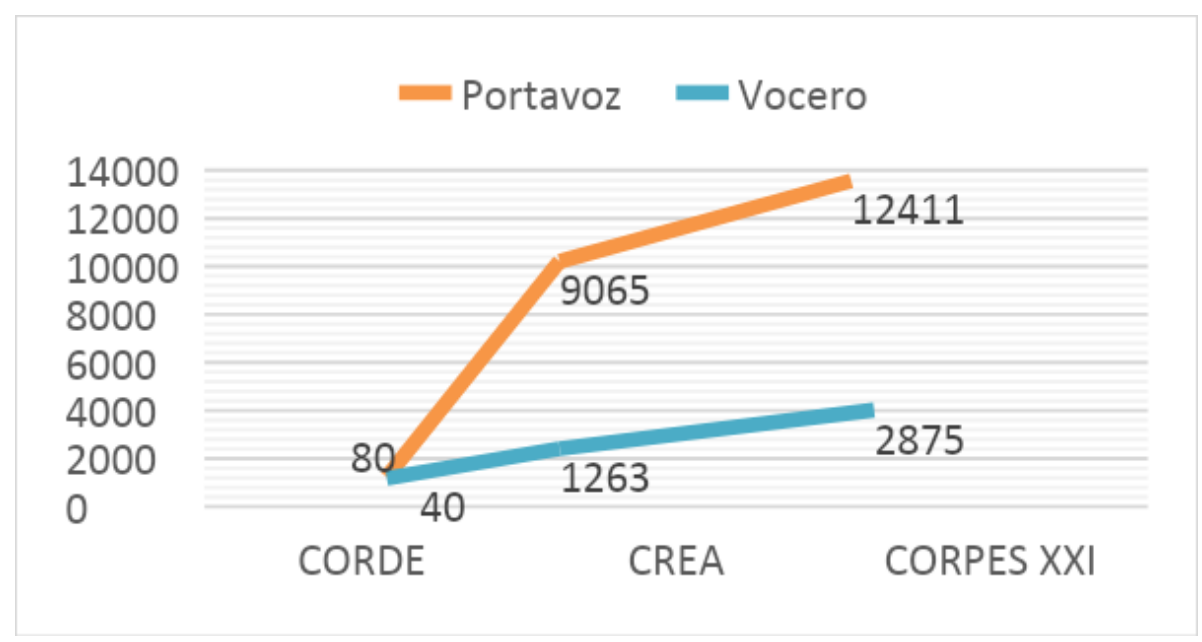

FIGURA 2.

\section{Evolución de la frecuencia de aparición de portavoz y vocero en los corpus}

Intentar sustituir hoy portavoz por vocero en el español peninsular ${ }^{25}$ no solo es ineficaz, sino que es impensable. Por mucho que sea un uso aplaudido por la norma, nuestra lengua sigue su camino en función de las voluntades de los hablantes y vocero no forma parte del repertorio léxico de la variedad peninsular. El tiempo marca las pautas de la lengua y, en esta 'disputa léxica', el vencedor es portavoz. Puede que en un futuro portavoza se extienda o no, no podemos saberlo en la actualidad, pero sí sabemos que vocero no se emplea asiduamente en el español peninsular.

\section{3. Árbitra: LA DUDA ANTE UNA NUEVA REALIDAD}

A lo largo del siglo XX, las mujeres han recorrido un largo y arduo camino hasta conseguir autonomía y emancipación. Han dejado de ser un colectivo invisibilizado gracias a su incorporación al mercado laboral, a los espacios de investigación y, en definitiva, a todos los ámbitos de la vida comunitaria. Dentro de esta esfera pública también se encuentra el deporte.

Recientemente, estamos viviendo una eclosión del deporte femenino, unida a la reivindicación de las deportistas de condiciones laborales paritarias respecto a sus compañeros varones. Es evidente que se ha avanzado notablemente en estas cuestiones, intentando erradicar la ideología sexista que rodea el mundo del deporte. Pese a ello, la realidad dista mucho de la igualdad perseguida por las mujeres.

Numerosos patrocinadores no avalan a equipos femeninos, lo que implica una falta de financiación y genera directamente unas condiciones laborales y salariales distantes a las del deporte masculino. En efecto, la estructura de la desigualdad social, que otorga posiciones diversas a cada sexo, también se implantó en el deporte. Mas si consideramos la tradicional y distinta asociación de cualidades fisiobiológicas a cada uno de ellos: la fragilidad es algo de las mujeres, el 'sexo débil'; la fortaleza y valentía de los hombres. Estas construcciones ideológicas diversas son los pilares del patriarcado, que aún subyace en nuestros días. Si bien se han superado paulatinamente los arcaicos modelos femeninos presentados por el franquismo, en los que esposa, madre y hogar eran las dedicaciones esenciales de la mujer, todavía se debe seguir reivindicando la igualdad entre sexos.

Esta distinta consideración de la mujer, en concreto en el ámbito deportivo, se evidencia en el uso de árbitra. En deporte, el árbitro es la persona que cuida de la aplicación del reglamento, sanciona las infracciones o fallos y valida los resultados. Esta acepción, en comparación con el resto de acepciones del término, ha pasado de suponer un $27.7 \%$ en 1975 a un $91.97 \%$ en 2016, como se observa en la Tabla 3. Evolución 
coherente con el papel que el deporte ha ido adquiriendo progresivamente en nuestra sociedad, hasta convertirse en uno de sus ejes culturales.

TABLA 3.

Evolución de la frecuencia de aparición de la acepción deportiva de árbitro en los corpus

\begin{tabular}{|c|c|}
\hline & Acepción 'deporte' \\
\hline $\mathbf{1 2 5 0}-1975$ (CORDE) & $27.7 \%$ \\
\hline $\mathbf{1 9 7 5 - 1 9 9 0}$ (CREA) & $79.3 \%$ \\
$\mathbf{1 9 9 0 - 1 9 9 5}$ (CREA) & $84.8 \%$ \\
$\mathbf{1 9 9 6 - 2 0 0 0}$ (CREA) & $87.8 \%$ \\
\hline $\mathbf{2 0 0 1 - 2 0 0 4}$ (CREA) & $91.83 \%$ \\
\hline $\mathbf{2 0 0 4 - 2 0 1 6}$ (CORPES) & $91.97 \%$ \\
\hline
\end{tabular}

En este apartado, se analizará la evolución sociohistórica de esta acepción de árbitro ${ }^{26}$, siguiendo los mismos parámetros de estudio que los del segundo apartado: observación de las muestras extraídas de los corpus del español y comparación de las definiciones en las distintas ediciones de los diccionarios.

Morfológicamente, el término árbitro marca el género mediante flexión, por lo que encontramos árbitro para el masculino y árbitra para el femenino. El problema con este término es el contrario de portavoz: por qué aún hoy se usa la forma masculina árbitro para denominar a las mujeres si existe el desdoblamiento por flexión. Según las premisas del lenguaje inclusivo, este uso invisibilizaría a las mujeres que arbitran en el deporte. La respuesta, de nuevo, la encontraremos en la sociedad.

La escasa presencia de mujeres en el arbitraje genera dudas en los hablantes sobre cuál es su correcta denominación. Muchos de los hablantes rechazan usar una palabra no porque sea lingüísticamente incorrecta, sino porque 'les suena mal'. Árbitra es una de esas palabras subyugada a la fonética. Precisamente, este chirrido fonético viene propiciado por la falta de uso de la palabra. Además, si profundizamos en la cuestión fonética y en su uso normativo, el uso correcto sería 'el árbitra', pues árbitra comienza por /a/ tónica, fenómeno que encontramos en otras palabras de nuestra lengua como agua o hacha. Son femeninas, pero seleccionan, en singular, la forma $e l$ del artículo definido, en lugar de la forma femenina la. Si ya es insignificante el número de apariciones de la árbitro y árbitra, imagínense lo que supondría proponer a los hablantes, en su mayoría desconocedores de estas normas de fonética histórica, el uso del artículo masculino junto al término femenino (el árbitra): un auténtico desconcierto lingüístico.

Esta escasa frecuencia de uso del femenino, ya sea a través de la concordancia o de la flexión, parece proporcional al reducido porcentaje de mujeres árbitras en el deporte profesional (ni siquiera suponen el 3\%). Los datos extraídos del estudio avalan esta hipótesis, como reflejan la Figura 3 y la Tabla 4: 


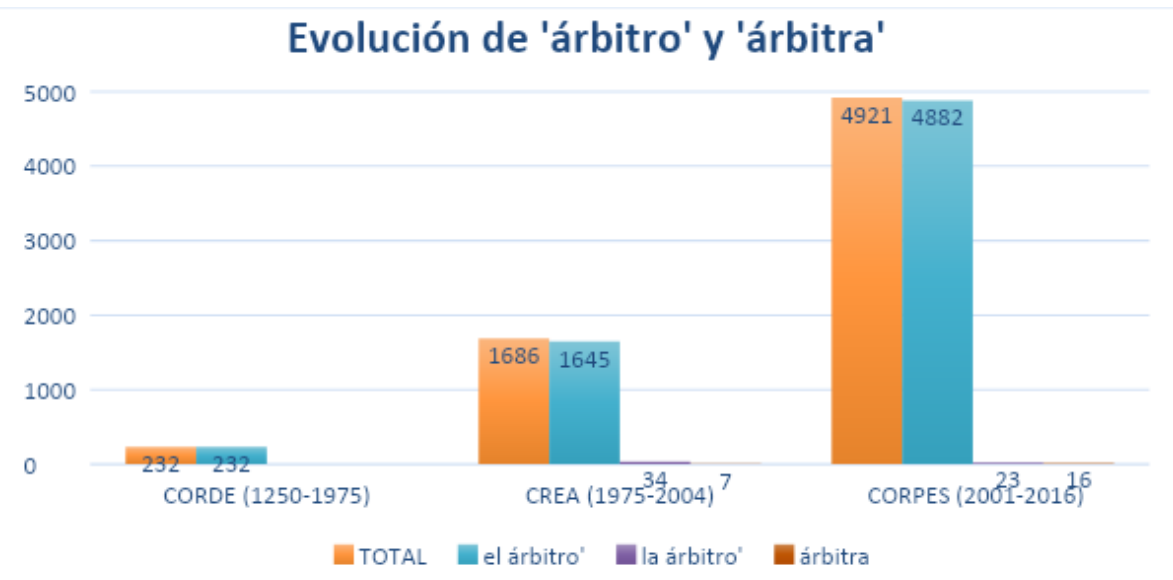

FIGURA 3.

Gráfico generado a partir de los datos del término árbitro y árbitra en los corpus

TABLA 4.

Desglose de datos extraídos de los corpus sobre los términos árbitro y árbitra

\begin{tabular}{|l|l|l|l|}
\hline & CORDE (1250-1975) & CREA (1975-2004) & CORPES (2001-2016) \\
\hline TOTAL & 232 & 1686 & 4921 \\
\hline El árbitro & $232(100 \%)$ & $1645(97.5 \%)$ & $4882(99.2 \%)$ \\
\hline La árbitro & 0 & $34(2 \%)$ & $23(0.46 \%)$ \\
\hline Árbitra & 0 & $7(0.5 \%)$ & $16(0.34 \%)$ \\
\hline
\end{tabular}

La edición del DRAE de 1983 recoge, por primera vez, la flexión de género árbitro/árbitra. Sería esperable que los datos extraídos de los corpus reflejasen un incremento de la frecuencia de aparición de árbitra desde los años ochenta. Si bien, como se observa en las Figura 3 y la Tabla 4, no es así. Hay que esperar hasta 1995 para encontrar la primera muestra de árbitra (CREA).

Más destacable es la preferencia por manifestar el género femenino a través de la concordancia, en lugar de la forma flexionada árbitra. La totalidad de los corpus revela un uso preferente de la forma común en cuanto al género, en detrimento de la forma árbitra.

En los corpus, también es reseñable el porcentaje, casi inexistente, que suponen las muestras femeninas, ya sea a través de la flexión o de la concordancia, en relación con las masculinas. De hecho, se observa un retroceso: se pasa del $2.5 \%$ de formas femeninas entre 1975 y 2004, al $0.8 \%$ entre 2001 y 2016.

Estos datos lingüísticos son un trasvase de la realidad social. Los datos extraídos en este estudio, sobre el uso de árbitro/árbitra, se corresponden con la situación del arbitraje femenino en la temporada 2018/19 ${ }^{27}$. Las árbitras profesionales de baloncesto y fútbol, los dos deportes más influyentes socioeconómicamente en España, no suponen el $3 \%{ }^{28}$ del total de colegiados oficiales.

En el desglose por categorías de la Figura 4 y la Figura 5, observamos cómo la presencia femenina aumenta en las categorías inferiores. La incorporación de la mujer al arbitraje presenta los mismos parámetros que los expuestos en el subapartado 2.1 sobre la política: a mayor responsabilidad y poder, más restricción hacia las mujeres. En este caso, categorías inferiores no profesionales y deportes minoritarios (como balonmano y voleibol, ver Tabla 5) presentan un mayor porcentaje de árbitras, siempre en inferioridad respecto a los árbitros. 


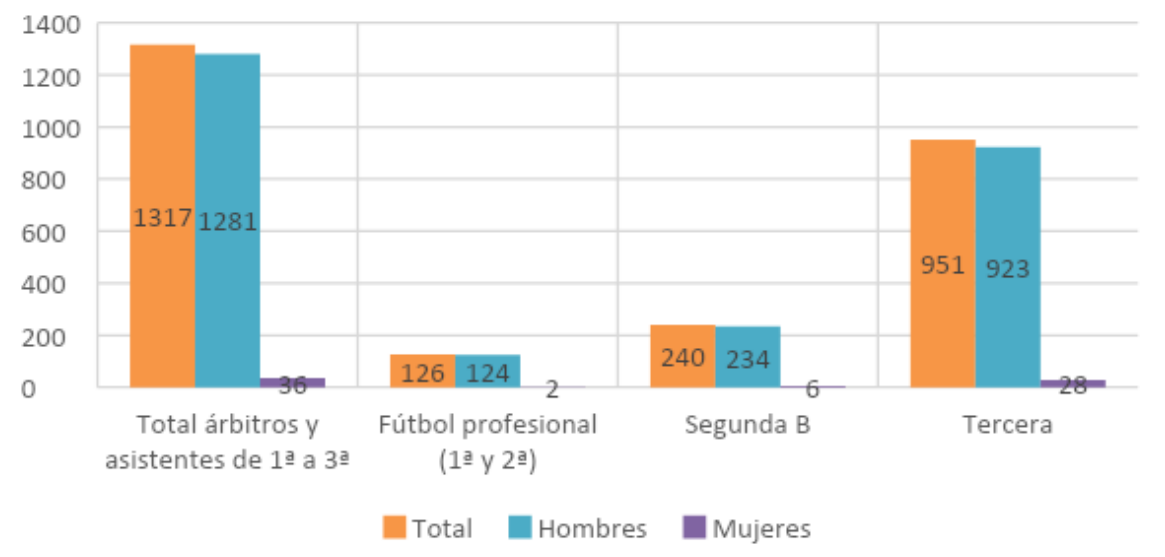

FIGURA 4.

Desglose por categorías del arbitraje del fútbol español (temporada 2018/2019)

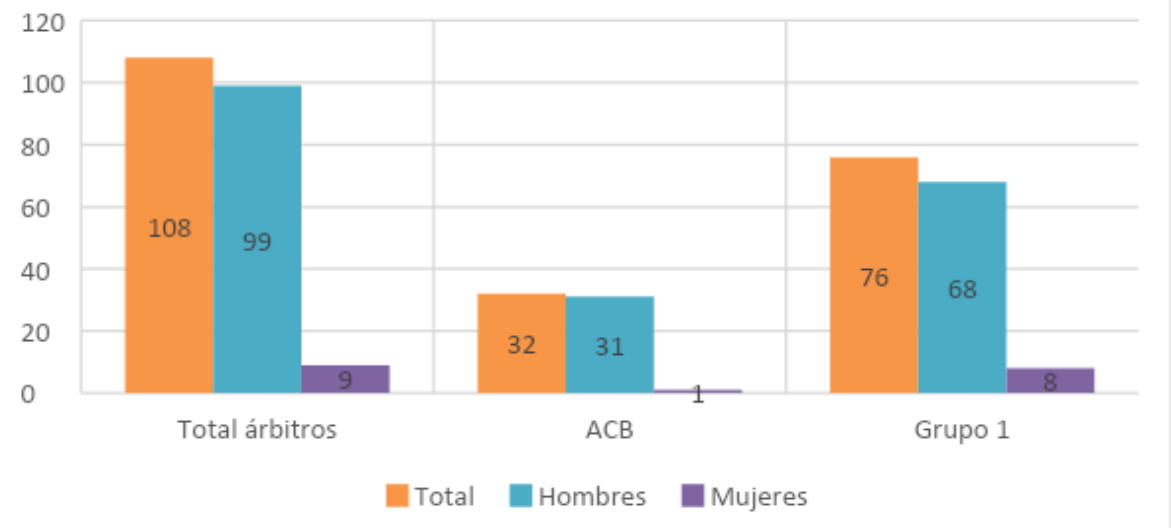

FIGURA 5.

Desglose por categorías del arbitraje del fútbol español (temporada 2018/2019)

TABLA 5.

Porcentaje de árbitras en distintos deportes españoles (temporada 2018/2019) ${ }^{29}$

\begin{tabular}{|l|l|l|}
\hline & Número de árbitras & Porcentaje \\
\hline Fútbol & $700 / 15000$ colegiados oficiales & $4.6 \%$ \\
\hline Baloncesto & $9 / 108$ colegiados de élite & $8.3 \%$ \\
\hline Balonmano & $24 / 226$ colegiados oficiales & $10.6 \%$ \\
\hline Voleibol & $5 / 30$ colegiados oficiales & $16.7 \%$ \\
\hline
\end{tabular}

Esta situación de inferioridad de la mujer en el arbitraje motiva, aún en la actualidad, usos de árbitro como sustantivo común en cuanto al género. Si leemos la prensa deportiva española, podremos extraer de una misma noticia, con facilidad, muestras de árbitra y la árbitro.

Un ejemplo de esta incoherencia lingüística sería el siguiente fragmento de Mundo Deportivo (2020, párr. 1): 
El bulo de 'la arbitra más sexy del mundo' inunda las redes. La noticia, que resultó ser falsa, de que Fernanda Colombo iba a ser la primera mujer árbitro en dirigir un partido en un Mundial ha corrido como la pólvora en internet (las negritas son nuestras).

Sin profundizar en el marcado contenido sexista de esta noticia, en tan solo dos líneas contabilizamos una marca de género a través de la flexión (árbitra) y otra a través de la concordancia (la árbitro).

A pesar de estos ejemplos, la tendencia de la prensa actual y, esperablemente de sus usuarios, es usar la flexión como marca de género. El reciente auge del deporte femenino y, más en concreto del fútbol, ha motivado el aumento de la frecuencia de árbitra en nuestra lengua. Tanto Marca como As, principales exponentes de la prensa deportiva española, incluyen ya en 2019 árbitra en su repertorio léxico. Hasta 2018, en las noticias de estos periódicos todavía se observaba una tendencia a marcar el género, exclusivamente, con la concordancia; práctica 'sociolingüísticamente coherente' con el menor interés generado por el deporte femenino en esa fecha.

Precisamente, ha sido en la temporada $2019 / 2020^{30}$, cuando una mujer, Guadalupe Porras Ayuso ${ }^{31}$, ha debutado como árbitra asistente en primera división, máxima categoría del fútbol español. Otro logro del arbitraje femenino ha sido el ascenso de Marta Huerta De Aza, quien se ha convertido en la árbitra con más categoría del fútbol masculino, al dirigir encuentros de la segunda división B.

El cambio morfológico de árbitra está en proceso, a pesar de normativizarse en 1983. Todavía no se ha estandarizado el uso del femenino flexionado árbitra en nuestra sociedad. La nueva situación social del deporte femenino, más igualitaria que años atrás, está impulsando el uso de esta forma, desde una perspectiva feminista, visibiliza más a la mujer.

Los avances de la mujer en la sociedad se producen día a día. En 1999, la profesora Vigara Tauste realizó un ensayo sobre la problemática de árbitra. En este trabajo, Vigara Tauste (1999, párr. 1) también admite la trascendencia del contexto sociocultural en la lengua: "a los argumentos lingüísticos sobre el uso de árbitra se suman otros de carácter cultural y social. La lengua no es, en sí misma, políticamente correcta (o incorrecta). Es simplemente una convención social". Efectivamente, los argumentos culturales y sociales marcaron el transcurso de árbitra los años siguientes a la publicación de este estudio. En 1999 no había apenas hueco para el deporte femenino, la mujer deportista estaba subordinada por la fuerte moral androcéntrica. Esta situación se está revirtiendo y, en 2018, las propias árbitras impulsaron una campaña para denunciar la violencia física y verbal que reciben en los terrenos de juego por el hecho de ser mujeres.

Los augurios de Vigara Tauste (1999) no eran nada alentadores para el futuro de árbitra, pues mencionaba que se inclinaría a desaparecer ante la tendencia mayoritaria de uso de la árbitro.

Los hablantes, al parecer, no quieren decir ni escribir la árbitra, y mucho menos el árbitra (sino la árbitro), como no
quieren decir ni escribir la música ni la cartera (sino la músico, la cartero) -aunque por razones sólo en parte coincidentes-,
pese a ser los femeninos fácilmente identificables de profesiones que ya ejercen las mujeres. Sólo el tiempo convertirá en
definitivamente convencional, al margen quizá de la Academia e incluso de ideologías, una u otra opción, o quizá -a saber
con qué razones- la alternancia. Con los años, seguramente, algunos de estos femeninos «nuevos» habrán echado raíces
y otros no: y parece muy probable que árbitra esté entre estos últimos... Pero hoy por hoy -admitámoslo-, periodistas y
periódicos, eventuales informantes como los que han colaborado para hacer posible estas notas lingüísticas, aficionados al
deporte y público en general tienen - tenemos- todavía «la palabra» (párr. 16).

Veinte años después de este ensayo, la sociedad ha cambiado y, con ella, su lengua. Árbitra ha pasado el juicio normativo de los hablantes: es la opción preferente para los periodistas deportivos, ámbito principal de difusión de este campo léxico, lo que facilitará su expansión. Incluso ya es reconocida por los hablantes como la opción 'lingüísticamente correcta' y aceptada por la norma. Parece que árbitra ha iniciado su proceso de convencionalización. Pero, como la propia Vigara Tauste reconoce, "solo el tiempo" (y la sociedad) “convertirá en definitivamente convencional la alternancia” (1999, párr. 16). 


\section{Conclusiones}

La realidad es el molde de nuestro repertorio léxico, portavoza y árbitra así lo manifiestan. Si bien el origen de estos términos es distinto (portavoza 'transgrede' conscientemente el género gramatical tradicional con fines reivindicativos, árbitra 'respeta' la regla de formación de femeninos en nuestra lengua), ambos materializan la nueva posición de la mujer en nuestra sociedad.

La evolución lingüística de los términos portavoza, alcaldesa, diputada y árbitra transcurre de forma paralela, nunca anticipada, a la evolución sociohistórica y política de la mujer. El diccionario, como recoge Gutiérrez Ordóñez (citado en Fanjul, 2014, párr. 6), "es un mero notario de los usos de la sociedad y la realidad se impone en él”. Durante la transición democrática, se redefinió la ciudadanía en tres planos, político, civil y social, desde el paradigma de los valores de la igualdad y la libertad. Estos avances colectivos no solo suponen una resignificación social, sino también una resignificación lingüística. Si profundizamos en los cambios lingüísticos estudiados en este trabajo, podemos situarlos en una de las fases de la teoría de Lüdtke (1998b):

En la primera fase, innovación, situaríamos portavoza. Un neologismo que pretende visibilizar más a las mujeres que desempeñan esa profesión y que ha suscitado un arduo debate sociolingüístico (quizás más socio que lingüístico).

En la segunda fase, difusión, encontraríamos árbitra. Término femenino reconocido como 'correcto' por la norma, que ha comenzado recientemente a convencionalizarse y a conformar el repertorio léxico de los hablantes.

En la tercera y última fase, resultado, estarían alcaldesa y diputada. Palabras que han superado, progresivamente, el juicio lingüístico de los hablantes, y de la norma, y hoy son aceptadas con total normalidad.

Alcaldesa y diputada ejemplifican cómo la sociedad impulsa la creación, la expansión y el afianzamiento de femeninos para profesiones. No podemos conocer ni profetizar sobre el futuro de portavoza. Muchos escépticos defienden sistemáticamente el uso de la forma común en cuanto al género portavoz y rechazan la ruptura de la norma lingüística de la forma flexionada. En 2019, portavoza no es un engendro lingüistico, es una palabra acomodada a una nueva realidad social. Sería un engendro en 1965, cuando una mujer consideraba onírico a la vez que inaccesible el escenario político. Este estudio demuestra que portavoza ha seguido los mismos patrones evolutivos que los términos alcaldesa, diputada y árbitra: en el momento en el que la mujer ocupa una determinada profesión, surge la necesidad de denominarla y nace la forma femenina. La lengua siempre va de lo concreto a lo abstracto, no al contrario.

Innovaciones en el género, como las de árbitra o portavoza, permiten distinguir pequeños matices, pero a la vez indispensables, en nuestra comunicación. Las palabras, como los seres vivos, tienen una vida y se adaptan a las exigencias del entorno (Escandell-Vidal, 2020, p. 246). Algunas nacen, se expanden y acaban siendo compartidas por toda una comunidad lingüística, como alcaldesa, diputada y, esperablemente, árbitra. Otros términos, no son tan afortunados y se quedan en el camino. Quizás portavoza gane (o no) la batalla a la muerte léxica y triunfe, a pesar de ser morfológicamente incorrecta. Solo el tiempo y el uso nos responderán a esta interrogación lingüística. Lo que sí se puede ratificar es que este neologismo ha generado un debate lingüístico, mediático y necesario, sobre la reivindicación de la situación de la mujer a través del género gramatical (Álvarez Mellado, 2018, párr. 8).

Los cambios se producen per se en las lenguas y vencen a ese inmovilismo conservador de la norma que aún impera. Como recoge Fernández Ordoñez (2012, párr. 6):

[...] es un hecho consustancial a la existencia histórica de las lenguas que los hablantes promuevan innovaciones lingüísticas, con independencia de que esas innovaciones cundan, prosperen y se adopten o no por parte de toda la comunidad lingüística. Están en su derecho. 
$\mathrm{Al}$ igual que no solo influyen argumentos lingüísticos en la evolución de estos términos, las resistencias a feminizar una profesión nunca se sostienen estrictamente sobre argumentos lingüísticos. Entonces, sería ilógico delimitar la polémica sobre el uso de portavoza a la lingüística cuando su origen y trasfondo es social. La lengua no es un arma, es un instrumento que se adapta a las necesidades de los hablantes. Y no, como apuntaban las lingüistas Pons, Horno y Marrero, no debieron preguntar a la RAE sobre el uso del lenguaje inclusivo. La causa del feminismo es mucho más seria y profunda que este debate sobre el género gramatical. Coincido con Álvarez de Miranda (2018, p. 90) en que el 'frente de batalla' principal de este movimiento es otro, pero se ha dado un gran paso, reconocer que comienzan a tambalearse los ancestrales pilares androcéntricos sobre los que se sustenta nuestra lengua.

\section{Bibliografía}

Álvarez de Miranda, P. (2018). El género y la lengua. Madrid: Turner Minor.

Álvarez Mellado, E. (9 de febrero de 2018). Sobre las portavozas. El Diario. Recuperado de https://www.eldiario.es/ opinion/zona-critica/portavozas-femenino-improbable_129_2800624.html

Analyse et Traitement Informatique de la Langue Française (ATILF). (1994). Trésor de la langue Française informatisé. [Versión en línea]. Recuperado de http://www.atilf.fr/tlfi

Ávila, M. (9 de febrero de 2018). La alternativa a "portavoza" que ya existe en español y puede utilizar Irene Montero. Cadena Ser. Recuperado de https://cadenaser.com/ser/2018/02/09/sociedad/1518171914_218581.html

Bengoechea, M. (2015). Lengua y género. Madrid: Síntesis.

Buxó Rey, M. J. (1988). Antropología de la mujer: cognición, lengua e ideología cultural. Barcelona: Anthropos.

Calero Fernández, M. A. (1999). Sexismo lingüistico análisis y propuestas ante la discriminación sexual en el lenguaje. Madrid: Fundación Invesnes.

Calvo, Y. (2017). De mujeres, palabras y alfileres. Barcelona: Edicions Bellaterra.

Clemente, Y. (28 de diciembre de 2018). El arbitraje femenino en el deporte español. El País. Recuperado de https:/ /elpais.com/elpais/2018/12/22/media/1545496557_956176.html

Corroto, P. (28 de enero de 2020). Tres lingüistas debaten sobre el lenguaje inclusivo: "No debieron preguntar a la RAE”. El Confidencial. Recuperado de https://www.elconfidencial.com/cultura/2020-01-28/rae-lenguaje-incl usivo-carmen-calvo_2429760/

Di Febo, G. (2003). Nuevo Estado, nacionalcatolicismo y género. En G. Nielfa Cristóbal (Ed.), Mujeres y hombres en la España franquista: sociedad, economia, politica, cultura (pp. 19-44). Madrid: Editorial Complutense.

Díez, A. (1 de agosto de 2019). Cuatro mujeres ocupan por primera vez las principales portavocías del Congreso. El Pais. Recuperado de https://elpais.com/politica/2019/07/30/actualidad/1564510061_325801.html

El Imparcial. (2018). Irene Montero (Podemos) acuña un nuevo término: "Portavozas". [Video]. Recuperado de htt ps://www.youtube.com/watch?v=OPHs3Ki2YkM

Escandell-Vidal, M. V. (2020). En torno al género inclusivo. IgualdaES, (2), 223-249.

Fanjul, C. (26 de octubre de 2014). Es la realidad la que moldea el nuevo diccionario, la RAE no hace ideología. Diario de León. Recuperado de https://www.diariodeleon.es/articulo/cultura/es-realidad-moldea-nuevo-diccionario-r ae-hace-ideologia/201410260200001470249.html

Fernández Ordóñez, I. (8 de marzo de 2012). El español y la igualdad real de los sexos. El Cultural. Recuperado de h ttps://elcultural.com/El-espanol-y-la-igualdad-real-de-los-sexos

Franco Rubio, G. A. (1986). La contribución de la mujer española a la política contemporánea: el régimen de Franco (1939-1975). En M. Á. Durán Heras y R. M. Capel Martínez (Eds), Mujer y sociedad en España (1700-1975) (pp. 239-264). España: Ministerio de Trabajo e inmigración, Instituto de la Mujer.

García Meseguer, A. (1977). Lenguaje y discriminación sexual. Barcelona: Montesinos.

García Meseguer, A. (1994).¿Es sexista la lengua española? Barcelona: Paidós. 
Gil, A., Miranda, D., Noguera, J., Pinilla, J. I., Leiva, J., Albarrán, N. y Mínguez, J. (4 de abril de 2019). Así está la situación del arbitraje femenino en España. Diario As. Recuperado de https://as.com/masdeporte/2019/03/04 /polideportivo/1551736446_903881.html

Grandes, A. (18 de febrero de 2018). Portavoza. El País. Recuperado de https://elpais.com/elpais/2018/02/10/opin ion/1518292837_483651.html

Grijelmo, A. (2019). Propuesta de acuerdo sobre el lenguaje inclusivo. Barcelona: Taurus.

Guerrero Salazar, S. (2017). La prensa deportiva española: sexismo lingüistico y discursivo. Córdoba: UCOpress.

Guerrero Salazar, S. (2019). Las demandas a la RAE sobre el sexismo del diccionario: La repercusión del discurso mediático. Doxa Comunicación, (29), 43-60.

Gutiérrez Ordóñez, S. (1989). Introducción a la Semántica Funcional. Madrid: Síntesis.

Gutiérrez Ordóñez, S. (10 de febrero de 2018). Sobre 'pilota', 'portavoza', 'miembra' y otros femeninos. El Mundo. Recuperado de https://www.elmundo.es/espana/2018/02/10/5a7df963ca474179478b4698.html

Islas Azaïs, H. (2005). Lenguaje y discriminación. D.F. México: Consejo Nacional para Prevenir la Discriminación.

Klemperer, V. (2001). La lengua del Tercer Reich. Apuntes de un filólogo. Barcelona: Editorial Minúscula.

Lakoff, G. y Johnson, M. (1980). Metáforas de la vida cotidiana. Madrid: Cátedra.

Lakoff, R, (1995). El lenguaje y el lugar de la mujer. Barcelona: Editorial Hacer.

Lledó, E. (2009). Guía de lenguaje para el ámbito del deporte. España: Instituto Vasco de la Mujer.

Lüdtke, H. (1998a). El cambio lingüistico. Bellaterra: Universitat Autònoma de Barcelona.

Lüdtke, H. (1998b). Diachronic semantics: towards a unified theory of language change? En A. Blanck y P. Koche (Eds.), Historical semantics and cognition (pp. 49-60). Berlin; New York: Mouton de Gruyter.

Marca. (2 de julio de 2019). Guadalupe Porras Ayuso será la primera árbitra asistente en debutar en Primera. Marca. Recuperado de https://www.marca.com/futbol/2019/07/02/5d1b3079e2704e66a48b458e.html

Marcos, J. (9 de febrero de 2018). Montero defiende decir "portavoza" para dar visibilidad a las mujeres. El Pais. Recuperado de https://elpais.com/politica/2018/02/08/actualidad/1518079927_468582.html

Mendívil Giró, J. L. (en prensa). El masculino inclusivo en español. Revista Española de Lingüistica. Recuperado de h ttps://www.academia.edu/40653925/El_masculino_inclusivo_en_espa\%C3\%B1ol

Moreno Cabrera, J. C. (2002). El motor de la economía lingüística: de la ley del mínimo esfuerzo al principio de la automatización retroactiva. Revista Española de Lingüistica, 32(1), 1-32.

Mundo Deportivo. (4 de mayo de 2020). Mundial de Rusia 2018: El bulo de 'la arbitra más sexy del mundo' inunda las redes. Mundo Deportivo. Recuperado de https://www.mundodeportivo.com/futbol/mundial/20180615/45 126472420/fernanda-colombo-arbitra-mas-sexy-mundo-bulo-mundial-de-rusia-2018.html

Nicolás M. E. y López, B. (1986). La situación de la mujer a través de los movimientos de apostolado seglar: la contribución a la legitimación del franquismo (1939-1956). En M. Á. Durán Heras y R. M. Capel Martínez (Eds), Mujer y sociedad en España (1700-1975) (pp. 365-390). España: Ministerio de Trabajo e inmigración, Instituto de la Mujer.

Pons, L. (10 de octubre de 2018). La vida empuja a la lengua: de señora a señoro. El País. Recuperado de https://ver ne.elpais.com/verne/2018/10/05/articulo/1538748293_739942.html

Prieto, L. J. (1967). Mensajes y señales. Barcelona: Seix-Barral.

Puleo García, A. (2002). Patriarcado. En C. Amorós (Dir.), 10 palabras clave sobre mujer (pp. 21-54). Pamplona: Editorial Verbo Divino.

Real Academia de Extremadura. (s. f.). Nosotras venimos dispuestos. Recuperado de https://raex.es/index.php/activid ades/3050-nosotras-venimos-dispuestos.html

Real Academia Española. (1994). Corpus diacrónico del español (CORDE). [Versión en línea]. Recuperado de http:/ /corpus.rae.es/cordenet.html

Real Academia Española. (2001). Diccionario de la lengua española. (22 ed.). [Versión en línea]. Recuperado de http s://www.rae.es/drae2001/ 
Real Academia Española. (2008). Corpus de referencia del español actual (CREA). [Versión en línea]. Recuperado de http://corpus.rae.es/creanet.html

Real Academia Española. (2012). Corpus del español del siglo XXI (CORPES XXI). [Versión en línea]. Recuperado de h ttps://apps.rae.es/CORPES/view/inicioExterno.view;jsessionid=71BE869EB5B60D168070081E4FF465C9

Real Academia Española. (2014). Diccionario de la lengua española. (23 ed.). [Versión en línea]. Recuperado de http s://dle.rae.es

Rodríguez López, C. (2013). Del pupitre a la tarima. Mujeres, ciencia y universidad. En Capel, R. M. (Ed.), Presencia y visibilidad de las mujeres: recuperando historia (pp. 283-312). Madrid: Abada Editores.

Sarlo, B. y Kalinowski, S. (2019). La lengua en disputa: Un debate sobre el lenguaje inclusivo. Ediciones Godot.

Suardiaz, D. E. (2002). El sexismo en la lengua española. Zaragoza: Libros Pórtico.

Vigara Tauste, A. M. (1999). ¿Árbitra? Recuperado de https://webs.ucm.es/info/especulo/cajetin/arbitra.html

\section{Notas}

1 Esta edición del diccionario es la primera que realizan de manera conjunta la RAE y la ASALE. Desde ese momento, ambas instituciones elaboran conjuntamente las obras normativas de la lengua española.

2 Afeminar consistía en 'hacer que un hombre perdiera su condición viril'.

3 Se entiende 'patriarcado' como la hegemonía masculina en las sociedades antiguas y modernas (Puleo, 2002, p. 21).

4 En palabras de García Meseguer (1994, p. 20), "un hablante incurre en sexismo lingüístico cuando emite un mensaje que, debido a su forma (es decir, debido a las palabras escogidas o al modo de enhebrarlas) y no a su fondo, resulta discriminatorio por razón de sexo".

5 De esta acepción parten expresiones como estudios de género, discriminación de género o violencia de género.

6 Si bien el inglés no presenta flexión de género gramatical, sí que tiene marcas de sexo, como los pronombres he o she o la palabra man. Precisamente, esta última se emplea para formar palabras compuestas, tales como fireman, y ha generado los mismos problemas que el uso genérico del masculino en español.

7 Se entiende por economía lingüística la tendencia de los hablantes a minimizar el esfuerzo a la hora de comunicarse.

8 El lenguaje inclusivo supuso un cambio en su denominación, siendo la actual 'Unidas Podemos'. Desde el partido defienden el cambio de género como una representación del alma feminista de las organizaciones de la coalición.

9 No es la primera vez que el género inicia un debate lingüístico en la política española. En 2008, Bibiana Aído (diputada del PSOE) generó una polémica similar al pronunciar miembros y miembras durante su intervención en el Congreso. También, en 1997, fue criticado el uso de jóvenes y jóvenas por la diputada socialista Carmen Romero, durante un mitin (Marcos, 2018).

10 El término español portavoz parece ser un calco semántico del francés portevoix, pues se documenta con anterioridad en lengua francesa y la acepción 'persona que está autorizada para hablar en nombre y representación de un grupo o de cualquier institución o entidad’, equiparable a la española, está incluida en el diccionario francés ya desde 1774 (ATILF, 1994):

1. 1680 «tuve ou cornet destiné à faire entendre la voix au loin» (RICH.) - esta acepción nos indica cómo se metaforizó el uso de un instrumento en una persona;

2. 1774 fig. en parlant d'une pers. (BEAUMARCHAIS, Mém. contre M. Goëzmands OEuvres compl., éd. Furne, t.3, p. 229: le porte-voix du comte de la Blache [...] chargeait ses plaidoyers des plus grossières injures);

3. 1850 expr. (FEUILLET, loc. cit.). Comp. de l'élém. de compos. porte-* et de voix*.

11 "Representante, portavoz. Boz" (ejemplo extraído del CORDE).

12 "Según la portavoz del grupo, Luisa Kennedy" (ejemplo extraído del CREA).

13 Porcentajes extraídos de los datos del CREA.

14 La propia Montero reconoció, irónicamente, su malestar por la no aceptación de portavoza por la RAE en una entrevista en LaSextaNoche.

$15 \mathrm{Al}$ menos en los documentos de los que se tiene constancia en los corpus.

16 En Mortal y Rosa (extraído del CORDE).

17 En ¿Por qué corres, Ulises? (extraído del CORDE).

18 No ha de olvidarse que, en 1900, el analfabetismo femenino alcanzaba en España el 71 \% (Rodríguez López, 2013, p. 285). 
Revista de Filología y Lingüística de la Universidad de Costa Rica, 2021, vol. 47, núm. 2, e46767, ...

19 Cayetana Álvarez de Toledo (Partido Popular), Adriana Lastra (Partido Socialista Obrero Español), Inés Arrimadas (Ciudadanos) e Irene Montero (Unidas Podemos).

20 En 1975, el porcentaje de mujeres que ejercían la alcaldía suponía el $0.71 \%$, tan solo 62 alcaldesas de 8635 alcaldías españolas (Franco Rubio, 1986, p. 417).

21 Pemán, J. M. (1970). Mis almuerzos con gente importante. Barcelona: Dopesa. (Extraído del CORDE).

22 Fragmento de El País, 29/09/1977, España. (Extraído del CORDE).

23 Actualmente, España es el país europeo con el Congreso más paritario, con un 47 \% de mujeres (Díez, 2019).

24 Per vocero contra suum vicinum; et qui hoc fecerit pectet: Anónimo, Fueros de Tudela que otorgó el rey don Alfonso I (1127) (extraído del CORDE).

25 En las variedades americanas, especialmente la rioplatense, el término vocero está muy extendido, en detrimento de portavoz, casi inexistente.

26 Acepción número 3 del DLE.

27 Datos extraídos de Clemente (2018) y Gil et al. (2019).

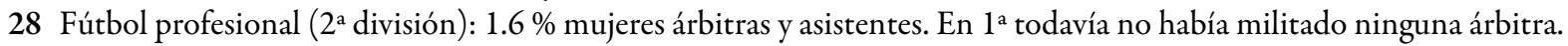
Baloncesto $(\mathrm{ACB}): 3.1 \%$ mujeres árbitras.

29 Gráfico elaborado a partir de los datos del siguiente artículo del diario As: “Así está la situación del arbitraje femenino en España" (Gil et al., 2019).

30 Marca (2 de julio de 2019).

31 Recientemente, Guadalupe Porras se ha convertido en la primera mujer en arbitrar la Copa del Rey de fútbol masculino (final disputada el 3 de abril de 2021 entre la Real Sociedad y el Athletic Club). 